\title{
Thematic Issue on Floods in the Danube basin - processes, patterns, predictions
}

\author{
Günter Blöschl ${ }^{1}$, Jan Szolgay ${ }^{2}$, Juraj Parajka ${ }^{1}$, Silvia Kohnová ${ }^{2}$, Pavol Miklánek ${ }^{3}$ \\ ${ }^{1}$ Institute for Hydraulic and Water Resources Engineering, Vienna University of Technology, Karlsplatz 13/222, A-1040 Vienna, Austria. \\ ${ }^{2}$ Slovak University of Technology in Bratislava, Faculty of Civil Engineering, Department of Land and Water Resources Management, \\ Radlinského 11, 81005 Bratislava, Slovakia. \\ ${ }^{3}$ Institute of Hydrology, Slovak Academy of Sciences, Dúbravská cesta 9, 84104 Bratislava, Slovakia.
}

\section{IMPORTANCE OF UNDERSTANDING FLOODS IN THE DANUBE BASIN}

It is amazing how many major floods have occurred in the Danube Basin in recent years. The August 2002 flood in the Upper Danube, in particular Austria, Slovakia and Hungary; the August 2005 flood in both the Upper Danube and in Romania; the April/May 2006 flood in Slovakia, Hungary, Bulgaria and Romania; the June 2013 flood which, in Passau, Germany, was almost as high as the largest known event in history in August 1501 (Blöschl et al., 2013); and an uncountable number of smaller-scale but extreme flash floods throughout the basin. While the Danube River and its tributaries have always experienced floods, damages have recently increased dramatically due to development pressure on the floodplains, and there are concerns that the flood flows themselves are increasing due to environmental change. Magnitude and changes in flood hazard depend on multiple climatic and non-climatic drivers (e.g. Kundzewicz et al., 2012) with relative site- specific significance. Climatic causes and their changes mainly include (intense) precipitation and snowmelt, non-climatic factors may comprise e.g. runoff generation processes and influence of storage capacities in catchments and rivers (e.g. Hall et al., 2014). Flood management is therefore high on the political agenda, and became one of the priorities of the recent Slovak Presidency of the EU Council.

Flood management in most of the Danube basin has recently experienced a radical transformation due to the EU Flood Risk Directive (European Union, 2007). The Directive stipulates a basin-scale perspective - as opposed to the traditional local measures - and an integrated perspective that considers a portfolio of management measures - as opposed to the traditional focus on structural flood protection alone. This diversity of management options has resulted in new and revisited research challenges for hydrology:

Understanding the rainfall-runoff processes causing local and regional floods, and their catchment response, to be able to better extrapolate to extreme floods;

Understanding how catchments and floodplains retain water under a diverse set of management options and flood magnitudes to assess downstream effects;

Understanding future changes in the flood risk as brought about by global and local environmental change.

Forecasting floods accurately and with known skill to assist in evacuation and other emergency measures;

Mapping the flood risk in inundation areas to assess potential damage; and

Estimating the probabilities not only of flood peaks but also of volumes to help design retention basins and other water structures.
The Hydrological Sciences are called upon to provide the necessary process understanding and methodology to address these challenges and assist integrated flood risk management in an efficient and robust way. The thematic issue on "Floods in the Danube basin - processes, patterns, predictions" of the Journal of Hydrology and Hydromechanics aims at contributing to these extremely important challenges with a focus on the Danube and its tributaries. It is a contribution to the Regional collaboration of the Danube countries in the framework of the International Hydrological Programme of UNESCO.

The Thematic Issue has been organised along three dimensions - "processes, patterns, and predictions" with the rationale of first aiming to understand the processes associated with floods (processes); next observing patterns in space and time and try to explain them by these processes (patterns); and finally using the knowledge gained to make predictions about future floods (predictions). Below we will briefly summarise the main findings of the contributions to the Thematic Issue and will put them into context.

\section{FLOOD PROCESSES}

Flash floods tend to exhibit very non-linear flood response and, since they are often not well observed due to the small catchment sizes, methods for estimating event rainfall and discharge are essential. Hlavčová et al. (this issue) test discharge peaks estimated by post-event analyses for three major flash flood events in Slovakia, using a distributed rainfallrunoff model, and suggest that the method can give reliable results and helps understand the rainfall-runoff relationship for such extreme events. In a regional analysis they find that the specific peak discharges decrease with catchment area, as would be expected, and the strength of that decrease can be mainly explained by the spatial organisation of the rainstorms. The decrease is stronger than, e.g., that for Mediterranean flash floods because of the small storm sizes.

While most floods are driven by rainfall alone, some floods, such as the April 2006 Morava flood, have an important snow melt component, often in combination with rainfall (i.e. rainon-snow). Understanding snow accumulation and melt processes can therefore assist in more accurate flood forecasting and peak flow estimation. Krajčí et al. (this issue) explore the patterns of snowmelt runoff generation in a small catchment in the Tatra Mountains and highlight the very large spatial variability of both snow depth and snow water equivalent and temporal dynamics of snowmelt measured by lysimeters. This variability diminishes the spatial representativeness of point measurements of snow, underlining the importance of using spatial snow patterns for testing distributed hydrological models. Krajčí et al. (this issue) test a distributed model against snow patterns in 
their catchment, in a similar way as Nester et al. (this issue) at a much larger scale and in an operational context. Both studies emphasise the benefit of using this information.

Flood processes occurring in the landscape, due to both rain and snow melt, are modulated by the river system processes. Hydrologists are particularly interested in the dynamics of the inundation areas, the propagation of the flood wave along the stream network and downstream effects of any alterations of the stream and its floodplain. These questions are addressed in three papers of this Thematic Issue. Craciunescu et al. (this issue) identify the inundation patterns along the Romanian Danube due to the April/May 2006 flood, which was the largest flood in this reach in the last 150 years. They test the accuracy of multi-scale satellite data from the MODIS (Moderateresolution Imaging Spectroradiometer) and ASTER (Advanced Spaceborne Thermal Emission and Reflection Radiometer) sensors, and build an on-line platform that allows exploring the space-time dynamics of the inundations. The propagation of flood waves along the Danube is analysed by Bačová-Mitková et al. (this issue). They use an non-linear storage (KalininMilyukov-Nash) cascade model to back-calculate travel times of the flood waves and investigate potential catastrophic floods, guided by the August 1501 event. While storage cascades are computationally efficient, they do not explicitly account for any anthropogenic changes of the floodplains. These can be explored by two-dimensional hydrodynamic models, as used by Skublics et al. (this issue). They examine the effect of river training and the construction of levees on the flood peaks at the Upper Danube, and obtain the somewhat surprising result that extreme floods are now attenuated more strongly than during historical (pre-training) conditions. This is because the retention areas are now filled later than previously, which points to the need for controlled flood retention systems in order to maximise flood peak retention.

\section{FLOOD PATTERNS}

The spatial distribution of floods at the tributaries of the Danube is controlled by climatic, landscape and geological features. In particular the role of climate drivers can be explored by examining the time of the year floods occur. Jeneiová et al. (this issue) find that, in the high elevation parts of the Upper Danube basin, floods tend to occur more often in summer than in winter. The timing of the occurrence is more consistent than that at lower elevations, pointing to the role of seasonal storms, antecedent soil moisture and snow processes, all contributing to different flood types. The spatial distribution of such flood types (synoptic, snowmelt, and flash floods) is investigated in more detail by Szolgay et al. (this issue) for part of the Upper Danube basin, with a focus on the statistical relationship between the peaks and volumes of flood events belonging to different types. They find the peak-volume relationships of flash floods to be different from those of the other flood types mainly because the peak-volume correlation increases more strongly with event magnitude, which points to a stronger climatic and a weaker catchment control (see also Hlavčová et al., this issue). Szolgay et al. (this issue) find that Extreme-Value type models of the peak-volume relationship fit the data best in small and mid-sized catchments. This is in contrast to the finding of Papaioannou et al. (this issue) of a best fit of Archimedean type models that show lower correlations at large event magnitudes. The difference may be due to Papaioannou et al. (this issue) focusing on the main Danube, including the lower reaches, where the diversity of flood generation and propagation processes may be much larger than for the smaller catchments analysed by Szolgay et al. (this issue).

Temporal patterns are equally important as spatial patterns, in particular with the renewed interest in long-term hydrological variability due to environmental change (Montanari et al., 2013). Pekárová et al. (this issue) identify a shift of the runoff regime of the entire Danube from summer/autumn to winter/spring in the $20^{\text {th }}$ century which they attribute to both warmer temperatures and the construction of reservoirs. They also find that small floods have increased and that the rises and recessions of such floods are faster, which is consistent with the retention effects estimated by Skublics et al. (this issue) for the Upper Danube.

\section{FLOOD PREDICTIONS}

Operational flood management is increasingly relying on accurate flood forecasts with longer lead times of a couple of days. Recent trends in flood forecasting therefore include the use of quantitative precipitation forecasts, updating the forecasts with on-line runoff measurements, and ensemble approaches that allow predictions not only of the most likely flood discharges but also their expected skill. Experience from the operational use of such a forecasting system in the Upper Danube basin is reported by Nester et al. (this issue). They show that the predictions of the expected skill are consistent with the skill obtained by comparing the forecasts with the actual flood observations. They also show that the skill decreases with the forecast lead time and increases with the size of the catchment area. This finding may give guidance on the minimum size of the catchment area flood management wishes to use such forecast.

Svoboda et al. (this issue) take a longer term perspective and predict extreme rainfall characteristics until the end of the $21^{\text {st }}$ century for the Czech Republic including the Moravian tributaries of the Danube. They analyse the output from a number of Regional Climate Models in terms of event rainfall and suggest that event rainfall depths and the average event intensity is expected to increase. All other things remaining the same, this finding would imply that also floods are likely to increase, although other controls such as changes in catchment soil moisture will also play an important role (Blöschl et al., 2015). An alternative approach to the same problem is proposed by Šraj et al. (this issue). They find that annual precipitation is a more robust indicator of flood changes than event precipitation in their study catchments, as it is a proxy of event precipitation, antecedent soil moisture and the catchment disposition to runoff response as a result of landscape evolution. They propose a method for estimating flood probabilities under non-stationary conditions that uses future annual precipitation as simulated by climate models. In their catchments, a $10 \%$ increase in annual precipitation is expected to lead to an $8 \%$ increase in the 10 year flood.

Finally, Brenner et al. (this issue) compare methods for mapping buildings that are at risk of flooding, and combine the building information with flood hazard zones. For two case study areas they show that orthophotos allow more accurate mapping than the usual cadastral maps. Additionally, orthophotos more readily facilitate a regular re-assessment of the damage potential.

\section{CONCLUDING REMARKS}

Floods will continue to occur in the Danube basin and it is essential that flood risk management is supported by state-of- 
the art hydrological expertise. The Guest Editors hope that the contributions of this Thematic Issue will help address the key flood challenges we are facing today and in the near future. The Guest Editors also hope that the Thematic Issue will further strengthen the hydrological collaborations within the Danubian countries in a number of arenas. Lastly, the Guest Editors would like to warmly thank all the authors who have contributed to this Thematic Issue.

\section{REFERENCES}

Blöschl, G., Nester, T., Komma, J., Parajka, J., Perdigão, R.A.P., 2013. The June 2013 flood in the Upper Danube basin, and comparisons with the 2002, 1954 and 1899 floods. Hydrology and Earth System Sciences, 17, 51975212.

Blöschl, G., Gaál, L., Hall, J., Kiss, A., Komma, J., Nester, T., Parajka, J., Perdigão, R.A.P., Plavcová, L., Rogger, M., Salinas, J.L., Viglione, A., 2015. Increasing river floods: fiction or reality? Wiley Interdisciplinary Reviews: Water. doi: 10.1002/wat2.1079.

European Union, 2007. Directive 2007/60/EC of the European Parliament and of the Council of 23 October 2007 on the assessment and management of flood risks. Official Journal of the European Union, L 288/27-34
Hall, J., Arheimer, B., Borga, M., Brázdil, R., Claps, P., Kiss, A., Kjeldsen, T.R., Kriaučiūnienè, J., Kundzewicz, Z.W., Lang, M., Llasat, M.C., Macdonald, N. McIntyre, N., Mediero, L., Merz, B., Merz, R., Molnar, P., Montanari, A., Neuhold, C., Parajka, J., Perdigão, R.A.P., Plavcová, L., Rogger, M., Salinas, J.L., Sauquet, E., Schär, C., Szolgay, J., Viglione, A., Blöschl, G., 2014. Understanding flood regime changes in Europe: a state-of-the-art assessment. Hydrol. Earth Syst. Sci., 18, 2735-2772. www.hydrol-earth-systsci.net/18/2735/2014/

Kundzewicz, Z.W. (Ed.), 2012. Changes in Flood Risk in Europe. Special Publication No. 10, IAHS Press, Wallingford, Oxfordshire, UK, pp. 516+xvi

Montanari, A., Young, G., Savenije, H.H.G., Hughes, D., Wagener, T., Ren, L.L., Koutsoyiannis, D., Cudennec, C., Grimaldi, S., Blöschl, G., Sivapalan, M., Beven, K., Gupta, H., Arheimer, B., Huang, Y., Schumann, A., Post, D., Srinivasan, V., Boegh, E., Hubert, P., Harman, C., Thompson, S., Rogger, M., Hipsey, M., Toth, E., Viglione, A., Di Baldassarre, G., Schaefli, B., McMillan, H., Schymanski, S.J., Characklis, G., Yu, B., Pang, Z., Belyaev, V., 2013. "Panta Rhei - Everything Flows": Change in hydrology and society - The IAHS Scientific Decade 2013-2022. Hydrological Sciences Journal, 58, 1256-1275. doi: 10.1080/02626667.2013.809088. 